\title{
Cardiac pacing reduced non-accidental falls in older adults with cardioinhibitory carotid sinus hypersensitivity
}

Kenny RA, Richardson DA, Steen N, et al. Carotid sinus syndrome: a modifiable risk factor for nonaccidental falls in older adults (SAFE PACE).J Am Coll Cardiol 2001 Nov 1;38:1491-6.

QUESTION: In older adults with cardioinhibitory carotid sinus hypersensitivity (CSH) presenting with a non-accidental fall (defined as coming to rest on the ground or another lower level not because of an accident or known medical cause), does cardiac pacing reduce subsequent non-accidental falls?

\section{Design}

Randomised (unclear allocation concealment*), unblinded,* controlled trial with 1 year of follow up.

\section{Setting}

A hospital in Newcastle upon Tyne, UK.

\section{Patients}

175 patients $\geqslant 50$ years of age (mean age 73 y, 59\% women) with cardioinhibitory $\mathrm{CSH}$ who reported to the emergency department because of a non-accidental fall. Exclusion criteria included cognitive impairment (MiniMental State Examination score $<24$ ), a medical cause for the fall within 10 days of presentation, an accidental fall, blindness, contraindication to carotid sinus massage (CSM), and use of drugs known to cause hypersensitivity to CSM. Follow up was $91 \%$.

\section{Intervention}

Patients were allocated to receive a rate-drop response physiological dual chamber pacemaker implant $(\mathrm{n}=87)$ or standard (non-pacing) treatment $(\mathrm{n}=88)$.

\section{Main outcome measures}

Number of falls without loss of consciousness and episodes of syncope.

\section{Main results}

Patients with pacemakers had fewer falls without loss of consciousness than did those in the control group (mean $4.1 / y$ y $9.3 / \mathrm{y}$, odds ratio $0.42,95 \%$ CI 0.23 to $0.75)$. The groups did not differ for episodes of syncope $(\mathrm{p}=0.063)$.

\section{Conclusion}

In older adults presenting with a non-accidental fall and cardioinhibitory carotid sinus hypersensitivity, cardiac pacing reduced subsequent non-accidental falls.

*See glossary.

\section{COMMENTARY}

In elderly people, falls can lead to substantial morbidity and mortality. ${ }^{1}$ Furthermore, CSH is a frequent cardiovascular cause of syncope. ${ }^{2}$

In this study by Kenny et al, the incidence of falls in patients who received a pacemaker was reduced by $70 \%$. Only those with a history of recurrent falls had a reduced incidence of syncope; overall, the groups did not differ for reduction in syncope.

Older adults who present with falls or syncope should be thoroughly evaluated. Studies have shown that the diagnostic yield of a comprehensive multidisciplinary assessment is high. ${ }^{3}$ This finding has profound medical, psychological, and economic importance. Cardiovascular causes remain the most common cause of syncope and signify a poor prognosis. Iatrogenic causes usually related to polypharmacy should be identified and rectified.

Although pacing is a simple intervention with a considerable beneficial effect in this patient population, only $16 \%$ of patients had a cardioinhibitory or mixed response that qualified them to receive a permanent pacemaker. $80 \%$ of patients who had syncope during carotid sinus massage had amnesia, raising the possibility that syncope may be more prevalent in patients who present with falls.

In establishing the efficacy of cardiac pacing for falls related to $\mathrm{CSH}$, this study points to the need to look for this disorder in elderly people presenting with non-accidental falls.

Munther Homoud, MD

Tufts University School of Medicine

Boston

Massachusetts

USA

1 Sattin RW. Falls among older persons: a public health perspective. Anпи Rev Public Health 1992;13:489-508.

2 McIntosh SJ, Lawson J, Kenny RA. Clinical characteristics of vasodepressor, cardioinhibitory, and mixed carotid sinus syndrome in the elderly. Am J Med 1993;95:203-8.

3 Youde J, Ruse C, Parker S, et al. A high diagnostic rate in older patients attending an integrated syncope clinic. J Am Geriat Soc 2000;48:783-7.
Sources of funding: National Health Service Cardiovascular Research World Development Programme; Research into Ageing; Medtronic.

For correspondence: Professor R A Kenny, Royal Victoria Infirmary, Newcastle upon Tyne, UK. r.a.kenny@ncl.ac.uk. 